\title{
Çocuklarda Obezite, Obezite İlişkili Hipertansiyon ve Risk Faktörleri
}

\author{
Obesity, Obesity-Related Hypertension and Risk Factors in Children
}

\author{
Salim EKİCİ, Serpil DİNÇER
}

Kahramanmaraş Sütçü İmam Üniversitesi Tip Fakültesi Çocuk Sağlığı ve Hastalıkları AD, Kahramanmaraş

Geliş tarihi: 05.05.2020 Kabul tarihi: DOI: 04.06.2020, DOI: $10.17517 / \mathrm{ksutfd} .732576$

\section{Özet}

Çocukluk çağı obezitesi dünya çapında en önemli halk sağlığı sorunlarından biridir. Hem gelişmiş hem de gelişmekte olan ülkelerde aşırı kilo ve obeziteprevalansı artmaktadır. Bu artmış prevalans, obezite ile ilişkili komorbid hastalıklarda artışa neden olmuştur. Bu hastalıklardan bir tanesi de obezite ilişkili hipertansiyondur. Burada, çocuklarda obezite ve hipertansiyon genel tanım ve ölçüm yöntemlerinden, sıklığından ve nedenlerinden bahsedilecek, aralarındaki ilişki gözden geçirilecek ve obezite ilişkili hipertansiyon mekanizmalarına değinilecektir.

Anahtar Kelimeler: Çocuk, hipertansiyon, obezite

\begin{abstract}
Childhood obesity is one of the most important worldwide public health problems. Overweight and obesity prevalence is increasing in both developed and developing countries. This increased prevalence has led to an increase in the obesity-related co-morbid diseases. One of these diseases is obesity-related hypertension. Herein, the relationship between hypertension and obesity in children, definiations, measurument methods, frequency will be reviewed and obesity-related hypertension mechanisms will be discussed.
\end{abstract}

Keywords: Children, hypertension, obesity

Yazışma Adresi: Serpil Dinçer KSÜ Tip Fakültesi Pediatri AD, Kahramanmaraş Tlf: 05325753418 e-mail: drserpildincer@gmail.com ORCID No (Sirasiyla): 0000-0001-5881-7302, 0000-0003-0653-6546 


\section{GİRIŞ}

\section{Çocuklarda Obezite}

Obezite, dünya sağlık örgütü tarafından vücuttaki yağ dokusunun çok fazla olması veya yağ miktarının vücut kütlesine oranının artması olarak tanımlanabilen; genetik ve sosyokültürel çevrenin de etkilediği kronik bir hastalıktır. Tüm dünyada yetişkinlerde olduğu gibi, çocuklarda da obezite sıklığının giderek arttığı öngörülmektedir. Çocukluk çağında başlayan obezite, yetişkin yaşta görünen obezite ile karşılaştırıldığında daha uzun süre kişinin yaşamını etkilediğinden kronik hastalıklar açısından daha önemlidir.

\section{Çocukluk Çağı Obezitesinin Tanımı ve Ölçüm yöntemi}

Obezite taramasında ve tanımlamasında dünyada en çok kabul gören metod vücut kitle indeksi (VKİ) hesaplamasıdır (1). VKİ; kilogram cinsinden vücut ağırlığının metre cinsinden boy uzunluğuna bölünmesi ile elde edilir. Anormal VKİ yaş ve cinsiyete göre spesifikpersentil eğrilerinde değerlendirilir. İki yaş üzeri çocuklarda VKİ, 85. persentilin üzerinde ise aşırı kilolu, 95. persentilin üzerinde ise obez veya aşırı kilolu, 99. persentilin üzerinde ise morbidobez olarak değerlendirilir $(1,2)$. İki yaş altındaki çocuklarda ise boya göre ağırlık obezite ve aşırı kiloyu değerlendirmede kullanılır (3).

VKİ değeri ile cilt kıvrım kalınlığı ve vücut dansitometri yöntemleriyle ölçülen vücut yağ miktarı arasında kuvvetli ilişki vardır. Cilt kıvrım kalınlığı, ölçüm tekniğine bağlı sorunlar nedeniyle her zaman güvenilir bulunmamaktadır. Ayrıca çocuklarda yaşla beraber toplam vücut yağının arttığı; fakat cilt altı yağ miktarının sabit kaldığı saptanmıştır. Bu nedenle yağ dokusunun farklı vücut bölgelerinde birikmesi söz konusudur. Bu dağılımı saptamak için en çok kullanılan yöntem, dokuların farklı geçirgenliğe sahip olmasına dayanan biyoelektrikselimpedans analizidir. Bunun dişında, su ya da hava ortamında vücut ağırlığı ölçümü, ultrasonografi, bilgisayarlı tomografi ya da manyetik rezonans görüntüleme de kullanılmaktadır (4).

\section{Obezite sıklığı ve risk faktörleri}

Dünya çocuk nüfusu arasında tahmin edilen yaygınlık \%6.7'dir ve 2020'de \%9 olması beklenmektedir (5). Bir meta-analiz çalışmasına göre Türkiye'de 1990-2015 yılları arasında prevalans \%0.7 ila \%7.1 arasında artmıştır (6) ve tahmini prevalans \%10'un üzerindedir (7).Genel olarak yurdumuzdaki obezite sıklığ 1 Avrupa bölgesindeki ülkelere yakindir (8).

Çocuklarda obezite çok faktörlüdür. Genetik yatkınlık, kültürel, çevresel ve davranışsal farklılıklar enerji alımı ile enerji harcaması arasındaki dengeyi bozarak obezitenin oluşumuna katkı sağlar. Enerji içeriği yüksek olan besinler, büyük porsiyonlu beslenme, fastfood, şekerli içeceklerden oluşan kötü beslenmenin ve hareketsiz yaşamın obezite oluşumunda rol oynadığı belirtilmektedir (9). Teknolojinin iler- lemesi fiziksel aktivitenin azalmasına, yüksek enerji ve şeker içeren gıdalara ulaşımın ve bunları tüketimin kolaylaşmasına yol açmaktadır. Çocukların günde 2-3 saatten fazla televizyon, video oyunları, bilgisayar ile zaman geçirmesi fiziksel aktiviteyi azaltırken, besin alımına ve beslenme sıklığında artışa neden olur (10). Epidemiyolojik çalışmalar, süt çocukları, çocuklar ve ergenlerdeki kısa uyku süresinin obezite gelişimi ile ilişkili olduğunu kanıtlamıştır $(11,12)$.

Annedeki gebelik diyabeti fetüsü hiperinsülinizme maruz bırakır ve yaşamın ileri evrelerinde obezite gelişimine katkı sağlar. İn utero kötü beslenme çocukluk ve ergenlik dönemindeki obezite gelişimi ile yakın ilişkilidir (13).

Obeziteye eşlik eden önemli hastalıklar olabilir. Tip 2 diyabet, kalp hastalığı, hipertansiyon, metabolik sendrom, insülin rezistansı, hiperandrojenizm, astım, uyku apnesi, non-alkolik karaciğer hastalığı, birtakım kardiyovasküler hastalıklar, ortopedik sorunlar (epifiz kayması, tibia vara, spondilolistezis gibi), cilt sorunları (akantozis nigrikans, keratozis pilaris), nörolojik sorunlar (psödotümör serebri, tinnitus, baş ağrısı) örnek verilebilir (5,14-16).

\section{Çocuklarda Hipertansiyon}

Çocuklarda hipertansiyon (HT), ortalama sistolik ve/ veya diyastolik kan basıncının bir hafta ara ile en az üç ölçüm sonrası cinsiyet, yaş ve boya göre 95 persentil veya üzerinde olması şeklinde belirtilmektedir $(5,17)$. Çocukluk çağında yaklaşık \%1-5 oranında görüldügü düşünülen HT sıklığının son yıllarda hızla arttığı görülmektedir (18). Hipertansiyon prevalansındaki artıştan sorumlu tutulan en önemli nedenlerden biri obezitedir. Beslenme alışkanlıklarındaki değişiklik (fazla kalorili, yağlı ve tuzlu yiyecek tüketimi), çevresel faktörler ve fiziksel aktivitedeki azalmaya bağlı olarak obezite prevalansı dünya genelinde artmakta; bu artış \%16’lara varmaktadir (19).

\section{Hipertansiyon Sıklığı ve Obezite İlişkisi}

Vücut kitle indeksi 90. persentil ve üzeri olan çocuklarda HT sıklığı 2.5-3.7 kat artmaktadır (20). Obezite derecesini gösteren VKİ arttıkça ofis kan basıncı ölçümlerinde anlamlı artış saptanmaktadır. Vücut kitle indeksi değeri arttıkça, hastaların özellikle 24 saatlik sistolik ve gece sistolik KB (SKB) değerleri artmaktadır. Gece sistolik ve diyastolik yaşam içi kan basıncı (YİKBİ) ölçümleri metabolik sendromu olanlarda anlamlı olarak daha yüksek bulunmaktadır (21).

Obez çocuklarda insülin direnci indeksi (Homeostasis model of assesment-insülin resistance/ HOMA-IR) değerleri arttıkça gece sistolik YİKBİ değerleri artmaktadır. Yapılan çalısmalarda obez çocuklarda insülin rezistansı olanların hem SKB hem de DKB'lerinin daha yüksek olduğu gösterilmiştir (16). Bu nedenle obez olgular içinde insülin direnci olanların, KB yüksekliği ve özellikle gece KB ölçümleri açısından 
daha yakın izlenmesi önerilmektedir (22). Metabolik sendromlu hipertansif olgularda hipertansif retinopati, mikroalbüminüri sıklığı anlamlı olarak daha fazla olup, sol ventrikül kitlesinde ve miyokardiyal kalınlık indeksindeki artış daha belirgindir. Öte yandan yine obez çocuklarda atriyal fibrilasyona yatkınlık oluşturan kalpte elektromekanik gecikmenin de olduğu saptanmıştır $(15,23)$. Tüm bu nedenlerle obez çocukların HT açısından değerlendirilmesi önem kazanmaktadır. Obez çocuklarda HT' ye neden olacak mekanizmalar aşağıda açıklanmaya çalışılmıştır.

\section{Obezitede Hipertansiyon Mekanizmaları}

Obezite ile ilişkili HT’nin patofizyolojisinde rol oynayan mekanizmalar arasında otonomik fonksiyon bozukluğu, yüksek insülin ve leptinin düzeyleri, vasküler yapı ve fonksiyonlarda değişiklikler, böbreklerde görülen değişiklikler ve renin anjiotensin aldosteron sistemi (RAAS)'nin aktivasyonu, diyette artmış fruktoz alımı, ürik asit yüksekliği gösterilebilir. Tüm bu mekanizmalar arasında en önemlisinin otonomik fonksiyon bozuklukları olduğu öngörülmektedir $(5,24)$.

\section{Otonomik Fonksiyonlardaki Bozukluklar:}

Sempatik sinir sisteminde hiperaktivite; kalp hızı $(\mathrm{KH})$ ve KB değişkenliğinde artış gibi kardiyovasküler bulgulara ve plazma katekolamin düzeylerinde artı̧s gibi nörohumoral bulgulara neden olmaktadır. Uzun dönem sempatik sistem aktivasyonuna bağlı olarak ortaya çıkan periferik vazokonstrüksiyon ve renaltübüler sodyum reabsorbsiyon artışı KB' de yükselmeye neden olur. Obez çocuklarda obez olmayan olgulara göre artmış $\mathrm{KB}$ ve $\mathrm{KH}$ değişkenliği gösterilmiştir (25). Obezitede gösterilen sempatik sistem aktivasyonuna eşlik eden sempatik ve parasempatik sistemlerin dengesindeki farklıkların da otonom fonksiyon bozukluklarına neden olduğu düşünülmektedir. Parasempatik ve sempatik sistemlerin dengesindeki değişikliklerin nedeni tam olarak bilinmemekle birlikte; insülin, leptin gibi çeşitli hormonların etkilerine bağlı olabileceği öngörülmektedir (26).

\section{Hiperinsülinemi:}

Obezite ile HT ilişkisi incelendiğinde dikkat çeken en önemli hormonal patolojilerin başında insülin direnci ve hiperinsülinemi görülmektedir. İnsülin rezistansı, periferik dokuların (örneğin kas, karaciğer ve yağ dokusu) hormonun etkilerine göreceli duyarsızlığını gösterir. İnsülin rezistansı; adipositlerin lipolitik etkileri nedeniyle, büyük miktarda serbest yağ asidi ve adipokin salgılanmasının bozulmasına yol açar, her ikisi de insülin duyarlılığının modülasyonunda rol oynar (16). Obezhipertansif hastalarda, insülinin karaciğer tarafından alımının azalması sonucu hiperinsülinemi oluşur. Hiperinsülinemi, sempatik sinir sistem aktivasyonu ve vasküler düz kas proliferasyonu aracılığı ile total periferik direnci arttırırken; renal sempatik sistem aktivasyonu ve aldosteron artışı üzerinden sodyum reabsorbsiyonunu, dolayısıyla plazma hacmini arttırmasına katkı sağlamaktadır (27).

\section{Hiperleptinemi:}

Obezite ile ilişkili HT'den sorumlu diğer önemli bir hormon ise leptindir. Leptin, yağ dokudan salınan ve enerji harcanmasında düzenleyici olan bir peptiddir. Obezlerdeleptin sinyalinde bir bozukluğa ya da leptin etkisine karşı oluşan dirence bağlı olarak serum leptin düzeyleri artış göstermektedir. Artmış leptin seviyeleri ile bağıntılı olarak fazla kilolu ve obezhipertansif olgularda artmış KB ve kalp hızı seviyeleri olduğu tespit edilmiştir (27).

\section{Vasküler Yapı ve Fonksiyonlarda Değişiklikler:}

Obezite bir çeşit vasküler ve sistemik inflamasyon durumudur. Bu inflamasyonun başlıca belirteçleri: insülin direnci, yüksek plazma leptin ve düşük adiponektin seviyeleri, artmış plazma glukoz ve serbest yağ asitleridir. Artmış yağ dokudan salınan inflamatuarsitokinlerin de vasküler düz kaslar üzerine etkileri olduğu gösterilmiştir $(5,28)$. Obezite bu etkileşimlerle endotele etki ederek proinflamatuar ve protrombotik bir sürece yol açar ve HT gelişimine katkı sağlar. Bazı çalışmalarda vaskülerendotelyal yapı değişikliklerinin HT etiyolojisinde katkı sağladığı belirtilmiştir (29).

\section{Renal Değişiklikler:}

Hipertansiyon gelişiminin en önemli nedenlerinden biri artmış sodyum reabsorbsiyonuilevolüm artmasıdır. Kan basıncı arttığında, diürez artışı ile ekstrasellüler sıvı ve venöz dönüşün azalması sağlanmakta; kardiyak debinin azaltılması ile KB’nin düşmesi sağlanmaktadır. Kan basıncı düştüğü zaman ise su ve tuz tutularak KB normale getirilmeye çalışılmaktadır. Obezitenin erken dönemlerinde, glomerül hasarı ve nefron kaybı olmadan önce renaltübülerreabsorbsiyonun artması ile primer sodyum retansiyonu olmaktadır. Fazlalaşan sodyumreabsorbsiyonunatriürez yetersizliği oluşturmakta; sodyum alımı ve atılımı arasındaki denge KB artışı ile sonuçlanmaktadır (29).

Obezitede, böbrek etrafında artmış yağ dokusu direkt olarak böbreğe basıya yol açarak HT gelişimine de neden olmaktadır. Bası; interstisyel basınç artışı, medüller kan akımında azalma ve tübüler kompresyon ve sodyum emiliminde artışa neden olmaktadır (27). İnterstisiyelhücre sayısı artışı ve lipidden zengin materyalin artışı, böbrek parankiminde hasarlanma ve böbreklerde büyümeye neden olmaktadır (29).

\section{Renin-Angiotensin-Aldosteron Sistemi'nin Aktivasyonu:}

Renin-Angiotensin-Aldosteron Sistemi (RAAS), tübüllerden sodyum geri alımında rol oynamaktadır. Obezite ilişkili HT'de başlıca rolü RAAS ve sempatik sinir sisteminin oynadığ 1 düşünülmektedir. Birçok çalışmada obezitede plazma renin aktivitesi, plazma anjiotensinojen aktivitesi, anjiotensin II ve aldosteron değerlerinde artış olduğu anlaşılmıştır. AngiotensinII' nin böbreği etkileyerek KB'yi artırdığ de SSS üzerinden birtakım moleküllerin salınımını artırarak da KB artırmada etkili olabildiğine inanılmaktadır (30). 


\section{Diyetteki Fruktoz Miktarı:}

Fruktozun iştah açıı etkileri hakkında farklı çalışmalar vardır. Yüksek miktarda fruktoz içeren mısır şuruplarının kullanıma girmesinin obezite artışına katkıda bulunduğu gösterilmiştir (31). Yüksek fruktoz içeren diyetlerin hiperinsülinemi, insülin direnci, hipertrigliseridemi ve HT ile ilişkisi olduğu anlaşılmıştır. Günlük fruktoz tüketiminin 74 gramı geçmesi halinde adolesan ve erişkinlerde KB' de artı̧s saptanmaktadır. Yine adolesanlarda artan yüksek fruktoz içerikli mısır şurubu alımı ile SKB artışı ve ilişkili kardiyovasküler problemler arasında anlamlı ilişki olduğu ortaya çıkmıştır (32).

\section{Ürik Asit Yüksekliği:}

Pürin metabolizmasının bir yan ürünü olan ürik asit, sağlıkl yetişkinlerde hipertansiyon gelişimini öngörür $(33,34)$. Çocukluk çağında da yüksek ürik asit düzeylerinin obezite, metabolik sendrom ve HT ile yakından ilişkisi saptanmıştır. Ürik asit yüksekliği ile HT riskinde yaklaşık 1.6-2 kat artış gösterilmiştir. Preklinik çalışmalar ürik asidin kısmen RAAS, özellikle anjiyotensin dönüştürücü enzim (ACE) -anjiyotensinII-anjiotensin II tip 1 reseptör yolunu aktive ederek KB' nı arttırdığını göstermektedir (34). Hipertansif çocuk hastalarda yapılmış bir çalışmada, serum ürik asit düzeylerinin böbrek fonksiyonundan bağımsız olarak SKB ve diyastolik KB (DKB) ile ilişkili olduğu saptanmıştır. Ürik asit düzeyindeki her $1 \mathrm{mg} / \mathrm{dl}$ artışın, SKB' de 14 mmHg, DKB'de 7 mmHg artış yaptığı gösterilmişstir (35).

\section{Hipertansiyon Klinik ve Değerlendirme:}

Çocuklarda HT çoğunlukla bir şikâyet veya bulguya neden olmaz. Çoğu olgu klinik olarak belirsizdir. Bu nedenle 3 yaşından büyük çocuklarda her fizik muayenede kan basıncının ölçülmesi gerekliliği önem kazanmaktadır. Özellikle obezite, diyabet, renal hastalıklar, aort koarktasyonu gibi birtakım kardiyovasküler hastalıkları olan bireylerin daha sıkı takip altında olmaları önerilmektedir (36). Bunun yanında yaşamı veya hedef organı tehdit edici komplikasyonlara (hipertansif acil) da neden olabilir (37).

Kan basıncında sadece minimal yükselmeler saptanan çocuk ve ergenlerde ilave incelemeler yapılmadan önce hipertansiyonun kalıcılığına karar verilmelidir. Değerlendirmenin kapsamı çocuğun yaşı, hipertansiyonun seviyesi, hedef organ hasarının boyutu ve uzun dönem risk etmenlerinin varlığı ile alakalıdır $(38,39)$. Güncel kaynaklar 95. persentilin üzerinde sürekli hipertansiyonu olan tüm olguların tam olarak değerlendirilmesini öne çlkarmaktadır (40). Bu değerlendirme kapsamında beyaz önlük hipertansiyonunu da dışlamak adına 24 saatlik ambulatuar KB ölçümü yapılması daha uygundur (36).

\section{TEDAVİ ve ÖNLEM}

\section{Obezite}

Obeziteyi önlemek için gerekli önlemler erken çocukluk döneminden başlanarak alınmalıdır. Üç yaş altı bebekler ilk 6 ay yalnızca anne sütü almalı, 6 aydan sonra ek gidalar ile anne sütü bırakılmamalıdır. Biberon ile beslenenlerde ve ek gıdalara geçildikten sonra meyve suyu, tatlı içeceklerden ve karbonhidrat yüklü mamalardan sakınılmalıdır (41).

Tedavide ilk basamak yaşam tarzında değişiklikler olmalıdır. Glisemik indeksi yüksek olan gıdalar diyetten uzaklaştırılarak ve miktarı azaltılarak hızlı enerji alımının önüne geçilmelidir. Diyet sebze ve meyveden zengin olmalıdır. Beslenmenin bir diyetten çok sağllklı yaşam biçimi olduğu anlatılmalı ve ailenin de durumun içinde olduğu anlatılmalıdır (42). Ek olarak günlük 20 dakikalık rutin egzersizler yapilması teşvik edilmelidir. Ayrıca akademik olmayan ekran başı süresinin günde 1-2 saatin üzerinde olmaması tavsiye edilmelidir. Bireye psikososyal destek verilmesi de tedavi modaliteleri arasindadir (43).

Yukarda bahsedilen yaşam stili değişikliklerine rağmen kilo veremeyen bireylere medikal tedaviler başlanılmalıdır. Medikal tedavide ise başlica kullanılabilecek ilaçlar ise orlistat, metformin ve octreotittir. Bu tedaviler yine yaşam stili değişiklikleri ile devam ettirilmeli ve hasta yakın takip altında olmalıdır. Eğer 12 haftanın ardında VKİ’nde \%4’ün üzerinde bir düşüş görülmemişse medikal tedavi kesilmelidir. Ancak birtakım koşullar altında bariatrik cerrahiden yardım alınabilir (43).

\section{Hipertansiyon}

Tedavide amaç hedef organ hasarını önlemek ve kan basıncını düşürerek erişkin çağda ortaya çıkabilecek kardiyovasküler hastalıkları önlemektir. Hedef kan basıncı <130/80 $\mathrm{mm} H \mathrm{Hg}$ veya $S K B$ ve $D K B$ değerlerinin 90 . persentilin altında (hangisi daha düşükse) olmasıdır (36). Sıklıkla yaşam boyu izlem ve tedavi gerekeceğinden hasta ve aile bilgilendirilmeli, yaşam tarzının değiştirilmesi ve tedaviye uyum açısından önlemler alınmalıdır. Vücut kitle indeksinde $\% 10^{\prime}$ luk düşüş ile kan basıncında 8-12 mmHg arası azalma olabileceği anlaşılmıştır. Obez çocuklarda zayıflama programları uygulanırken başarıya ulaşmak için ailenin katılımı çok önemlidir. Bunun için diyet programları ile ailenin eğitimi ve egzersiz programlarının eklenmesi önem kazanmaktadır.

Diyette günlük alınan sodyum klorür miktarının 4-5 gr kadar kısitlamanın kan basıncını 8 mmHg' a kadar azalttığ anlaşılmıştır. Çocuk ve ergenlerin diyetlerinde günlük 2300 $\mathrm{mg}(100 \mathrm{mEq})$ sodyum miktarının aşılmaması gerekmektedir. Her hastada tuz kısıtlamasının faydaları açıkça gösterilememesine rağmen en azından yemeklere tuz eklenmemesi prehipertansif veya hipertansif hastalarda önem kazanmaktadır.

Hipertansif çocuğun hayat tarzının değiştirilmesi ve aktivitenin arttırılması hem kan basıncı hem de sağlı̆̆ı üzerine 
çok önemli katkı sağlar. Haftada 3-4 defa zirve kalp hızının \%60-85' ine ulaşan bir düzeyde aerobik egzersizlerin (merdiven çıkma, hızlı yürüme, bisiklete binme ve yüzme gibi) yapılması gerekmektedir.

Medikal tedaviye hasta yaşam tarzı değişikliklerine uyguladığı ancak KB düşüşü olmadığı takdirde başlanılmalıdır. Medikal tedavide amaç hastanın kan basıncını 95. persentil değerlerinin altına indirmektir.Ayrıca kronik böbrek hastalığı, diyabet ve hipertansif hedef organ hasarı varlığında 90. persentilin altında olması gerekir. İlaç tedavisine çoğunlukla tek ilaçla ve en düşük dozda başlanmalıdır. Etki elde sağlanıncaya kadar ilaç maksimum doza kadar arttırılmalı; yeterli etki sağlanamadığı (2-4 haftalık tedaviye rağmen) veya ilacın yan etkileri görüldüğü takdirde başka gruptan ikinci bir ilaçla (diüretikler) desteklenmelidir. Çocuklarda antihipertansif tedavi için kabul gören ilaç sınıfları; anjiyotensin dönüştürücü enzim inhibitörleri, uzun etkili kalsiyum kanal blokerleri, anjiyotensin reseptör blokerleri ve diüretiklerdir $(36,40)$.

Sonuç olarak; Okul çağı çocuklarında obezite ve ilişkili diğer hastalıklardan en önemlisi olan HT’un ilişkisi oldukça karmaşık ve gün geçtikçe önem kazanmaktadır.Çocukluk çağında sıklığı giderek artan obezitenin azaltılmasının, yukar1da anlatılan mekanizmalar üzerinden HT’nu da engelleyeceği öngörülmektedir.Bu nedenle okul çağı çocuklarının aldıkları besinlerin kalori, tuz ve fruktoz açısından sınırlı tutulması, günlük fiziksel aktivitenin arttırılması ile aşırı kilolu,obez ve hipertansif olmalarının önüne geçileceği gibi, erişkin çağda kardiyovasküler hastalıklı bireyler olma ihtimalleri de azalacaktır.

\section{KAYNAKLAR}

1. Mei Z, Grummer-Strawn LM, Pietrobelli A, Goulding A, Goran MI, Dietz WH. Va-lidity of body massindexcomparedwithother body-compositionscreeningindexesfortheassessment of body fatness in childrenandadolescents. Am J Clin Nutr 2002;75(6):978-985.

2. Barlow SE. Expert Committee recommendations regarding the prevention, assessment, and treatment of child and adolescent overweight and obesity: Summary report. Pediatr 2007;120(4):164-192

3. Kumar S, Kelly AS. Review of Childhood Obesity: From Epidemiology, Etiology, and Comorbidities to Clinical Assessment and Treatment. Mayo Clin Proc. 2017;92(2):251-265. 4.Lifshitz, F. Pediatric Endocrinology, 5th ed. New York: Informa Healthcare USA Inc., 2006.

5. Güneş H, Alkan Baylan F, Güneş H, Temiz F. Can Nesfatin-1 Predict Hypertension in Obese Children? J Clin Res Pediatr Endocrinol 2020;12(1):29-36

6. Çelmeli G, Çürek Y, Arslan Gülten Z, Yardımsever M, Koyun M, Akçurin S, et al. Remarkable Increase in the Prevalence of Overweight and Obesity Among School Age Children in Antalya, Turkey, Between 2003 and 2015. J ClinRes Pediatr Endocrinol. 2019;11:76-81.

7. Obezite tanı ve tedavi klavuzu. Türkiye Endokrinoloji ve Metabolizma Derneği. Turkey, Miki Matbacılık, 2018:16.

8. Hatun Ş. Çocukluk çağı obezitesinin dünya ve Türkiye'de sıklığı. Turkish J Pediatr Dis 2012;1(2):7-14
9. Malik VS, Schulze MB, Hu FB. Intake of sugar-sweetened beverages and weight gain: A systematic review. Am J ClinNutr. 2006;84:274-288.

10. Epstein LH, Roemmich JN, Robinson JL, Paluc RA, Winiewicz DD, JH Fuerch, et al. A randomized trial of the effects of reducing television viewing and computer use on body mass index in young children. Arch Pediatr Adolesc Med 2008;162:239245.

11. Taveras EM, Rifas-Shiman SL, Oken E, Gunderson EP, MW Gillman. Short sleep duration in infancy and risk of childhood overweight. Arch Pediatr Adolesc Med. 2008;162(4):305-311.

12. Liu X, Forbes EE, Ryan ND, Rofey D, Hannon TS, Dahl RE. Rapid eyemovement sleep in relationtooverweight in children and adolescents. Arch Gen Psychiatry 2008;65(8):924-932.

13. Dubois L, Girard M. Early determinants of overweight at 4.5 years in a population-based longitudinal study. Int J Obes (Lond) 2006;30(4):610-617.

14. Speiser PW1, Rudolf MC, Anhalt H, Camacho-Hubner C, Chiarelli F, Eliakim A, et al. Obesity Consensus Working Group. Childhood obesity. J Clin Endocrinol Metab 2005;90(3):187187.

15. Temiz F, Güneş H, Güneş H. Evaluation of Atrial Electromechanical Delay in Children with Obesity. Medicina (Kaunas). 2019;55(6):228

16. Güneş H, Güneş H, Temiz F. The Relationship Between Epicardial Adipose Tissue and Insulin Resistance in Obese Children. Arq Bras Cardiol. 2020 Mar 13. pii: S0066-782X2020005004203. doi: 10.36660/abc.20190197 [Epub ahead of print]

17. Candan C, Çalışkan S. Çocukluk çağında hipertansiyona yaklaşım: Derleme. Türk Pediatri Arşivi 2005;40:15-22.

18. Flynn JT, Daniels SR, Hayman LL, Maahs DM, McCrindle BW, Johnson RJ, et al. Ambulatory blood pressure monitoring in children and adolescents: A scientific statement from the American Heart Association. Hypertension 2014;63(5):1116-1135.

19. Sumboonnanonda A, Chongcharoensuk C, Supavekin S. Persistent hypertension in Thai children: Etiologies and outcome. Jour of Med Assoc Thai 2006;89(2):28-32.

20. Aghamohammadzadeh R, Heagerty AM. Obesity-related hypertension: epidemiology, pathophysiology, treatments, and the contribution of perivascular adipose tissue. Annals of Med 2012;44(1):74-84.

21. Gilardini L, Parati G, Sartorio A, Mazzilli G, Pontiggia B, Invitti C, et al. Sympathoadrenergic and metabolicfactors are involved in ambulatory blood pressurerise in childhood obesity. Jour of Hum Hyper 2008;22(2):75-82.

22. Lurbe E, Torro I, Aguilar F, Alvarez J, Alcon J, Pascual JM, et al. Added impact of obesity and insulin resistance in nocturnal blood pressure elevation in children and adolescents. Hypertension 2008;51(3):635-641

23. Mule G, Nardi E, Cottone S, Cusimano P, Volpe V, Piazza G, et al. Influence of metabolic syndrome on hypertension-related target organ damage. Jour of Inter Med 2005;257(6):503-513.

24. Awazu M. Hypertension. Avner ED, HarmonWE, Niaudet P, Yoshikawa N. In Pediatric Nephrology, 6th ed. Berlin Heidelberg: SpringerSpringerVerlag, 2009:1457-541

25.Becton LJ, Shatat IF, Flynn JT. Hypertension and obesity: Epidemiology, mechanisms and clinical approach. Indian Jour of Ped 2012;79(8):1056-1061.

26. Rabia F, Silke B, Conterno A, Grosso T, De Vito B, Rabbone I, et al. Assessment of cadiac autonomic modulation during adolescent obesity. Obes Res 2003;11(4):541-548.

27. Falkner B, Gidding SS, Ramirez-Garnica G, Wiltrout SA, West $\mathrm{D}$, Rappaport EB, et al. The relationship of body mass index and 
blood pressure in primary care pediatric patients. Jour of Ped 2006;148:195-200

28. Becton LJ, Shatat IF, Flynn JT. Hypertension and obesity: epidemiology, mechanisms and clinical approach. Indian J Pediatr 2012;79(8):1056-1061

29. Kotsis V, Stabouli S, Papakatsika S, Rizos Z, Parati G. Mechanisms of obesity-induced hypertension. Hyper Res 2010;33(5):386393.

30. Hall JE, Hildebrandt DA, Kuo J. Obesity hypertension: Role of leptin and sympathetic nervous system. Am Jour of Hyper 2001;14(6 Pt 2):103-115.

31. Bantle JP. Dietary fructose and metabolic syndrome and diabetes. Jour of Nutr 2009;139(6):1263-1268.

32. Khoury PR, Mitsnefes M. Age-specific reference intervals for indexed left ventricular mass in children. Jour of Am Soc of Echo 2009;22:709-714.

33. Sundström J, Sullivan L, D’Agostino RB, Levy D, Kannel WB, Vasan RS. Relations of serum uricacid to longitudinal blood pressure tracking and hypertension incidence. Hypertension 2005; $45: 28-33$

34. South AM, Shaltout HA, Nixon PA, Diz DI, Jensen ET, O'Shea $\mathrm{TM}$, et al. Association of circulatinguricacidandangiotensin-(1-7) in relation to higher blood pressure in adolescents and the influence of preterm birth. J Hum Hyper 2020 Apr 28. doi: 10.1038/s41371-020-0335-3. [Epub ahead of print]

35 Feig DI, Kang, DH, Johnson, RJ. Uricacid and cardiovascular risk. New Eng Jour of Med 2008;359(17):1811-1821.

36 Göknar N, Çalışkan S. New guidelines for the diagnosis, evaluation, and treatment of pediatric hypertension. Turk Pediatri Ars 2020;55(1):11-22.

37. Lubre E, Alcon JJ, Redon J. Epidemiology and concequences of childhood hypertension. In: Geary DF, Schaefer F (editors). Comprehensive Pediatric Nephrology. 1th ed. Philadelphia: Mosby Elsevier Inc; 2008. p. 637-44

38. Daniels SR. Consultation with the specialist. The diagnosis of hypertension in children: an update Pediatr Rev 1997;18(4):1315.

39. Norwood VF. Hypertension. Pediatr Rev 2002;23(6):197-208

40. National High Blood Pressure Education Program WorkingGroup on High Blood Pressure in Children and Adolescents. The fourth report on the diagnosis, evaluation, and treatment of high blood pressure in children and adolescents. Pediatr 2004;114(4):555-73.

41. Speiser PW1, Rudolf MC, Anhalt H, Camacho-Hubner C, Chiarelli F, Eliakim A, et al. Obesity Consensus Working Group. Childhood obesity. J Clin Endocrinol Metab. 2005;90(3):187187.

42. James J, Thomas P, Cavan D, Kerr D. Preventing childhood obesity by reducing consumption of carbonated drinks: cluster randomised controlled trial. BMJ. 2004;328:1237.

43. Styne DM, Arslanian SA, Connor EL, Farooqi IS, Murad MH, Silverstein JH, et al. Pediatric Obesity-Assessment, Treatment, and Prevention: An Endocrine Society Clinical Practice Guideline. J Clin Endocrinol Metab. 2017;102(3):709-757. 